THE WABASH CENTER

JOURNAL on TEACHING

\title{
Why Race and Culture Matter in Schools: Closing the Achievement Gap in America's Classrooms, 2nd edition
}

\author{
Tyrone C. Howard \\ New York, NY: Teachers College Press, 2019 ( $x x+183$ pages, ISBN 978-0-8077-6309-4, \\ \$28.77)
}

\section{Reviewed By}

Stan Chu llo

DePaul University

The need to close the achievement gap in America between African American, Native American, and Latinx students and their White student counterparts is an ongoing concern for educators, politicians, policy makers, parents, and American society in general. However, one does not often see a book that goes beyond ideological differences to offer an evidencebased study and a comprehensive diagnosis of the problem, while at the same time designing some evidence-based interventions and best practices. This is what Tyrone C. Howard has done in this impressive book.

This book argues that race and culture play decisive roles in both the teaching and learning processes. However, the book shows that there are other variables which also come into play in maintaining the poor educational outcomes for minority students, including the quality and commitment of teachers. The seven chapters of this book focus on three fundamental ideas: the data on the opportunity gap, Howard's diagnosis of the problem, and his design for intervention and best practices through case studies.

In chapters one and two, Howard analyses the data that show that there is a pervasive achievement gap in American schools between White students and African American, Native American, and Latinx students. The evidence offered is quite sobering in terms of how this nation is failing her young people from these racial groups. Chapter two uses data to demonstrate the changing demographics of America. Readers learn in this chapter that there is an urgent need to develop multicultural educational models that will not only meet the educational needs of minorities, but prepare both White and minority students to meet the changing cultural landscape of America. Howard argues that the changing demographics, tectonic cultural shifts, and diversity of today's America demand that we overcome current dominant and mainstream white normative education and embrace an inclusive and equitable education which meets the needs of racially and culturally diverse schools and societies.

Chapters 3 through 5 offer a diagnosis of the problem. The heart of the problem, Howard writes, is the prevalence of a deficit model of cultural understanding and normativity of Whiteness and associated epistemological frames and pedagogical practices which do not fulfil the requirements of culturally responsive pedagogy. The other elephant in the room is the pervasiveness of racism in American schools and society, most particularly anti-blackness. The author employs critical race theory to show the destructive impact of cultural modelling, color blindness, dominance pedagogy, and racial frames of reference, as well as how instructional and internal racism widen the achievement gap in American schools.

Chapters 6 and 7, to my thinking, offer the most original contributions of this book. The author offers some best practices for developing cultural competence, racial awareness, and culturally responsive pedagogy. Through a study of four schools, Howard identifies success stories in closing the achievement gaps. Using these, readers are given five qualities which produce high achieving students: visionary leadership, effective instructional practices, intensive academic intervention, explicit acknowledgement of race in the school, and parental and community engagement in a partnership between home and school.

This book is an important field manual for all teachers who care about equity and inclusive education. It describes how to create a safe school culture for every student no matter their background and offers some problem-solving strategies and pedagogical innovations that can promote student success and reduce prejudice in school, while creating an empowering school culture. The strength of the book is that Howard brings his own experience as both a teacher and a parent to the text. 
He also brings the experiences of many teachers into this text. The narrative method-using the stories of the joy and pain, hope and despair of many students-employed to illustrate points in this book appeals to me as a theologian and a teacher of religion. Religious educators who embrace the message of this book will find in it "a paradigm of possibility, a stand of empowerment, a framework of faith, a firm belief in the intellectual prowess of young people" (144) for accompanying young people from low-income and diverse backgrounds to unlock their intellectual prowess and realize their boundless God-given potentials and innate goodness. 